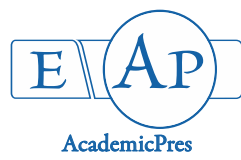

\title{
Evaluation of Drought Tolerance Selection Indices Using Grain Yield in Chickpea (Cicer arietinum $\mathbf{L}$.)
}

\author{
İrfan ERDEMCÍ
}

GAP International Agricultural Research and Training Centre 21110 Diyarbakır, Turkey; irfan_erdemci72@hotmail.com

\begin{abstract}
Among abiotic stresses, drought is undoubtedly one of the most important ones, that have great impact on crop growth and productivity worldwide. Therefore, identifying of plants' performance against drought stress and estimating drought tolerance become a necessary part of the breeding phase. The main purpose of the present study was to investigate the effect of several indices that combine drought tolerance and high yield potential in chickpea. The trials were conducted under both stressed and no-stressed environments for two growing seasons (2015/2016-2016/2017) in Southeast Anatolia Region of Turkey. Varyans analysis results showed that there were significant differences among genotypes regarding Yp, Ys, MP, MRP, GMP, REI, STI, MISTIk 1, MISTIk 2, HM, YI, PI, ATI, SNPI and RDY. The genotypes FLIP09-51C, FLIP97-503C and FLIP06-97C had high yield under non-stressed condition, while the genotypes FLIP09-51C, FLIP06-97C and 'Aksu' displayed high amount under stressed condition. Thus, the genotypes FLIP09-51C and FLIP06-97C were found as good candidates for commercial recommendation in both conditions. Spearman rank correlation matrix showed that drought indices were significantly related to each other. The yields in stress and no-stress conditions (Yp and Ys) showed a significant and positive correlation with MP, MRP, GMP, REI, STI, MSTIK1, MSTIK2 and HM and showed a negative correlation with PI and RDY. As a result, it has been found that MISTIK2, DI, HM, STI and YI can be used as optimal indicators for screening drought-tolerant genotypes, while FLIP09-51C, FLIP06-97C, EN934 and 'Aksu' varieties have been the most tolerant genotypes in terms of these indices examined in study.
\end{abstract}

Keywords: chickpea; correlation analysis; drought indices; seed yield

Abbreviations: ATI: Abiotic Tolerance Index; DF: Degrees of Freedom; DI: Drought Resistance Index; DTE: Drought Tolerance Efficiency; GM: Golden Mean; GMP: Geometric Mean Productivity; HM: Harmonic Mean of Yield; MISTIk2: Modified Stress Tolerance Index 2; MP: Mean Productivity; MRP: Mean Relative Performance; MSTIk1: Modified Stress Tolerance Index 1; PI: Superiority Index; R: Rank; RDI: Relative Drought Index; RDY: Relative Decrease in Yield; RI: Relative; Efficiency Index; SDI: Sensitivity Drought Index; SNPI: Stress/Non-Stress Production Index; SOV:; Source of Variation; SSI: Stress Susceptibility Index; SSPI: Stress Susceptibility Percentage Index; STI: Stress Tolerance Index; TOL: Tolerance; YI: Yield Index; Yp: Potential Yield; Ys: Stress Yield

\section{Introduction}

Chickpea (Cicer arietinum L.) is one of the most important edible legumes grown in marginal lands around the world. Its production is about 12.1 million tons from 12.7 million hectares cultivated land, with a mean seed yield of $95 \mathrm{~kg} \mathrm{ha}^{-1}$. Chickpea is produced on 351.687 hectares in Turkey and ranks fifth in the world after India, Australia, Myanmar and Pakistan (FAO, 2016). Among food legumes, chickpea is rich in nutritional compositions and does not contain significant quantities of any specific major anti-nutritional factors. Due to its high protein content, chickpea is used as a major protein source in most of developing countries. It is also an important pulses plant in cereal-legume planting rotation in many countries around the world (Zdemur et al., 2003). Biotic and abiotic stresses are important factors limiting the agricultural production in the world. From these abiotic stresses, drought causes severe yield losses in arid and semi-arid regions (Mollasadeghi et al., 2011).

Due to Ascochyta blight disease in chickpea, most of the chickpea production is done in marginal areas and as spring planting in many countries of the world. This situation causes terminal drought stresses during flowering, podding and seed filling period of plants in Turkey. Therefore, 
440

selection for drought tolerant chickpea genotypes is the most important objective for breeding to drought stress. Drought tolerance selection is not easy due to the happening of strong interactions between genotypes and the environment and restricted knowledge about the function and role of tolerance mechanisms. Hence, researchers have used different drought resistance indices to evaluate genetic differences in drought tolerance.

To appraise reaction of plant to drought stress, some selection index (SSI, MP, TOL, YSI, RDI, PI, STI, GMP, HM, YI and KiSTI) based on a mathematical relation between stress and optimal conditions have been recommended (Fischer and Maurer, 1978; Rosielle and Hamblin, 1981; Bouslama and Schapaugh, 1984; Blum, 1988; Lin and Binns, 1988; Fernandez, 1992; Gavuzzi et al., 1997; Farshadfar and Sutka, 2002).

Thus, the present study was conducted to (i) determine drought tolerance indices under stress and non-stress conditions, and (ii) identify some of chickpea genotypes reaction to drought stress.

\section{Materials and Methods}

\section{Growth conditions and research materials}

The research was conducted at two locations with different average rainfall amounts, namely Diyarbakır and Kuzlltepe, during 2016 and 2017, both of which are located in the Southeast Anatolia Region of Turkey. The favorable site (Diyarbakur) is located at $37^{\circ} 56^{\prime} \mathrm{N}$ latitude, $40^{\circ} 15^{\prime} \mathrm{E}$ longitude, at an elevation of $670 \mathrm{~m}$ above sea level. The soil of the trial area carried out in this locality is a clay loam. The average annual maximum and minimum temperatures are $22.6{ }^{\circ} \mathrm{C}$ and $8.8{ }^{\circ} \mathrm{C}$ respectively, and average annual precipitation is $485 \mathrm{~mm}$ (Anonymous, 2017). Kizlltepe station represents the stressed semi-arid site with $300 \mathrm{~mm}$ as mean rainfall. It is located at $37^{\circ} 19^{\prime} \mathrm{N}$ latitude, $40^{\circ} 58^{\prime} \mathrm{E}$ longitude, at an elevation of $490 \mathrm{~m}$. The soil is deep clay. The yearly average maximum and minimum temperatures are $26.4^{\circ} \mathrm{C}$ and $12.1^{\circ} \mathrm{C}$ respectively.

The research material consisted of fourteen Kabuli chickpea genotypes (Table 1) which included four check varieties ('Arda', 'Diyar-95', 'Azkan' and 'Aksu') and ten advanced breeding lines.

The field experiments were arranged in a randomized complete block design with three replications at both environments. The plots consisted of 4 rows that were $5 \mathrm{~m}$ long and spaced $0.30 \mathrm{~m}$. Seeds were planted with parcel machine at density of 45 seeds per square meter. The sowings were performed on the last week of November in both environments and harvestings were carried out on the last week of June for stressed fields and in the first week of July for non-stressed experimental site. Di-Ammonium Phosphate (DAP 18-46) fertilizer was used at the rate of $130 \mathrm{~kg}$ per hectare as source of $\mathrm{N}$ and $\mathrm{P}$ before sowing. Weeds were controlled by hand during crop growth and development.

\section{Calculation of indices}

The seed yield of each plot was evaluated based on $6 \mathrm{~m}^{2}$, and converted to the standard unit at metric kg per hectare. Drought indices were calculated using the consacrated formulas (Annex 1).

\section{Statistical analysis}

The correlation coefficients were calculated using the SPSS version 22. The experimental data were statistically analyzed for variance using JMP statistical software (SAS 2007). Differences were compared by Least Significant Difference Test (LSD) at alpha 0.05 .

\section{Results and Discussion}

\section{Analysis of variance}

Analysis of variance for both potential yield (Yp) and stress yield (Ys) indicated significant differences among the fourteen chickpea genotypes. Variance analysis of both the potential yield (YP) and the stress yield (YS) indicated significant differences among the genotypes. Also, significant differences were observed for the examined indices MP, MRP, GMP, REI, STI, MISTIk1, MISTIk2, HM, YI, PI, ATI, SNPI and RDY (Table 2).

The ranks of the chickpea according to each one of the drought tolerance indices are given in Table 3 . The average seed yield of the varieties under non-stressed conditions ranged from 3,954.4 ('Diyar-95') to 4,825.0 kg (FLIP09$51 \mathrm{C}$ ), while ranged from 2,384.4 ('Arda') to $3,044 \mathrm{~kg}$ in the stressed conditions. Besides, the average grain yield in nonstressed condition $(4,370.1 \mathrm{~kg})$ was higher than in stressed condition $(2,736.3 \mathrm{~kg})$. When the yields of the varieties were compared in two environments, the largest variation of yield was observed in 'Arda' variety, followed by FLIP97503C and 'Azkan' respectively. Maximum reductions in grain yield were observed in 'Arda' and FLIP97-503C genotypes, while the least amount of reductions in yields was observed in FLIP03-131C and FLIP06-93C genotypes (Table 3).

Fernandez (1992) classified plants according to their performance in stressful and stressless conditions to four groups: genotypes with high performance in both conditions (group A), genotypes with good performance

Table 1. List of the 14 chickpea genotypes used for the study

\begin{tabular}{cccccc}
\hline $\begin{array}{c}\text { Entry } \\
\text { code }\end{array}$ & Name & Origin & Entry code & Name & Origin \\
\hline 1 & EN 934 & TURKEY & 8 & FLIP06-93C & ICARDA \\
2 & FLIP03-112C & ICARDA & 9 & FLIP06-39C & ICARDA \\
3 & FLIP 03-131C & ICARDA & 10 & FLIP97-503C & ICARDA \\
4 & FLIP 03-104C & ICARDA & 11 & 'Arda' & TURKEY \\
5 & FLIP09-51C & ICARDA & 12 & 'Diyar-95' & TURKEY \\
6 & FLIP06-133C & ICARDA & 13 & 'Azkan' & TURKEY \\
7 & FLIP06-97C & ICARDA & 14 & 'Aksu' & TURKEY \\
\hline
\end{tabular}


Annex 1

\begin{tabular}{|c|c|c|}
\hline Index & Formula & References \\
\hline Mean productivity & $: M P=(Y p i+Y s i) / 2$ & Rosielle and Hamblin (1981) \\
\hline Mean relative performance & $: M R P=\left(Y_{s i} / Y_{s}\right)+\left(Y_{p i} i / Y_{p}\right)$ & Hossain et al. (1999) \\
\hline Stress susceptibility index & $: S S I=(1-(Y s i / Y p i)) /\left(1-\left(Y_{s} / Y \bar{p}\right)\right)$ & Fischer and Maurer (1978) \\
\hline Stress tolerance & $: T O L=Y p i-Y s i$ & Rosielle and Hamblin (1981) \\
\hline Geometric mean productivity & $: G M P=\sqrt{ }(Y p i \times Y s i)$ & Fernandez (1992) \\
\hline Relative efficiency index & $: R E I=\left(Y s i / Y_{s}\right) \times\left(Y p i / Y_{p}\right)$ & Hossain et al. (1999) \\
\hline Stress tolerance index & $: S T I=(Y s i \times Y p i) /(Y \bar{p})^{2}$ & Fernandez (1992) \\
\hline Modified stress tolerance index 1 & $: M S T I k I=\left((Y p i)^{2} /\left(Y_{\bar{p}}\right)^{2}\right) \times S T I$ & Farshadfar and Sutka (2002) \\
\hline Modified stress tolerance index 2 & $: M S T I k 2=\left(\left(Y_{s i}\right)^{2} /\left(Y_{s}\right)^{2}\right) \times S T I$ & Farshadfar and Sutka (2002) \\
\hline Harmonic mean of yield & $: H M=2 \times(Y p i \times Y s i) /(Y p i+Y s i)$ & Dadbakhsh et al. (2011) \\
\hline Yield Index & $: Y I=Y s i / Y_{s}$ & (Gavuzzi et al., 1997; Lin et al., 1986) \\
\hline Superiority index & $\begin{array}{l}: P i=\sum_{\mathrm{j}=1}^{\mathrm{n}} \frac{(X i j-M j)^{2}}{2 n} \\
\text { Where } \\
n-\text { the number of environments } \\
X i j-\text { the seed yield of the } i \text { th genotype in the } j \text { th environment } \\
\mathrm{M}=\text { Yield of the highest yielding genotype in the environment } j\end{array}$ & Lin and Binns (1988) \\
\hline Sensitivity drought index & $: S D I=(Y p i-Y s i) / Y p i$ & Farshadfar and Javadinia (2011) \\
\hline Relative drought index & $: R D I=\left(Y_{s i} / Y_{p i}\right) /\left(Y_{s} / Y_{p}\right)$ & Fischer and Wood (1979) \\
\hline Drought resistance index & $: D I=Y s i \times(Y s i / Y p i) /\left(Y_{s}\right)$ & Lan (1998) \\
\hline Golden mean & $: G M=(Y p i+Y s i) /(Y p i-Y s i)$ & Moradi et al. (2012) \\
\hline Abiotic tolerance index & $: A T I=((Y p i-Y s i) /(Y \bar{p} / Y s)) \times(Y p i \times Y s i)^{1 / 2}$ & Moosavi et al. (2008) \\
\hline Stress Susceptibility percentage index & $: S S P I=((Y p i-Y s i) /(2 \times Y \bar{p})) \times 100$ & Moosavi et al. (2008) \\
\hline Stress/non-stress production index & $: S N P I=\left[(Y p i+Y s i) /(Y p i-Y s i) \times(Y p i \times Y s i \times Y s i)^{I / 3}\right]^{I / 3}$ & Moosavi et al. (2008) \\
\hline Relative decrease in yield & $: \mathrm{RDY}=100-((\mathrm{Ysi} / 100) \times \mathrm{Ypi})$ & Farshadfar and Elyasi (2012) \\
\hline Drought tolerance efficiency & $: \mathrm{DTE}=(\mathrm{Ysi} / \mathrm{Ypi}) \times 100$ & Fischer and Wood (1981) \\
\hline
\end{tabular}

Table 2. Analysis of variance for yield performances of chickpea genotypes in non-stressed and stressed conditions and drought resistance indices

\begin{tabular}{cccccccc}
\hline SOV & DF & Yp & Ys & MP & MRP & SSI & TOL \\
\hline Genotype & 13 & $7491107^{* *}$ & $5219226^{* *}$ & $5122273.7^{* *}$ & $1.758^{* *}$ & $1.173^{\text {ns }}$ & $4931572^{\text {ns }}$ \\
Replication & 3 & 566794 & 601329 & 462032.4 & 0.181 & 0.264 & 488116 \\
Error & 95 & 13608602 & 12204302 & 3631305 & 1.325 & 8.441 & 37100589 \\
CV & & 8.65 & 13.1 & 5.49 & 6.0 & 3.06 & 13.80 \\
\hline SOV & DF & GMP & REI & STI & MSTIk1 & MSTIk2 & HM \\
\hline Genotype & 13 & $5491024^{* *}$ & $1.781^{* *}$ & $0.733^{* *}$ & $2.734^{* *}$ & $3.328^{*}$ & $5976366^{* *}$ \\
Replication & 3 & 534937 & 0.171 & 0.069 & 0.212 & 0.365 & 612815 \\
Error & 95 & 4616955 & 1.318 & 1.228 & 3.259 & 3.733 & 6495562 \\
CV & & 6.39 & 12.0 & 14.50 & 13.42 & 15.23 & 7.82 \\
\hline SOV & DF & YI & PI & SDI & RDI & DI & GM \\
\hline Genotype & 13 & $0.710^{* *}$ & $2.05 \times 10^{12^{* *}}$ & $0.161 \mathrm{~ns}$ & $0.451^{\text {ns }}$ & $0.607^{\text {ns }}$ & $107.21^{\text {ns }}$ \\
Replication & 3 & 0.086 & $1.98 \times 10^{11}$ & 0.028 & 0.074 & 0.094 & 7.93 \\
Error & 95 & 1.011 & $275 \times 10^{12}$ & 1.583 & 2.178 & 2.631 & 539.37 \\
CV & & 10.01 & 15.32 & 11.25 & 14.01 & 15.20 & 10.20 \\
\hline SOV & DF & $\mathbf{A T I}$ & SSPI & SNPI & RDY & DTE & $1607.56^{\text {ns }}$ \\
\hline Genotype & 13 & $2.94 \times 10^{13 *}$ & $634.21^{\text {ns }}$ & $842.12^{*}$ & $2.5510^{10^{* *}}$ & 284.56 & 15830.28 \\
\hline Replication & 3 & $2.26 \times 10^{12}$ & 64.79 & 107.42 & $2.45 \times 10^{9}$ & 12.80 &
\end{tabular}

SOV: source of variation; DF: degrees of freedom; ns: non-significant; ${ }^{* *}$ significant on 0.01 level. ${ }^{*}$ significant on 0.05 level 
442

only in stressless conditions (group B) or stressful stressless conditions (group D), and genotypes with low performance in both conditions (group C).

According to this classification, the FLIP09-51C, FLIP97-503C and FLIP06-97C, FLIP03-104C, EN934 and 'Aksu' genotypes had higher yield performances than the mean yields of the genotypes in both stressed and nonstressed conditions, and were located on the group A. Whereas 'Diyar 95', FLIP03-112C, FLIP06-39C, 'Azkan' and FLIP06-133C genotypes had lower yields than the average yields of the genotypes for both environments and were located on the group C. On the other hand, FLIP03131C and FLIP06-93C genotypes had higher yield performance than average yield for only stressed environments and were included in group D. However, the 'Arda' variety had higher yields than the average yield for stress-free environments and was included in group B. It was noteworthy that the FLIP 09-51 C and FLIP 06-97C genotypes performed well both under stressed and stressed conditions (Fig. 1).

Based on stress tolerance indices MP, MRP, GMP, REI, STI, MSTIk1, MSTIk2, HM and ranking method genotypes, FLIP09-51C, FLIP06-97C and 'Aksu' all with highly grain yield under stressed and non-stressed conditions were identified as drought tolerance genotypes. Other chickpea genotypes were identified as semi-tolerance or semi-sensitive to drought stress (Table 3). Genotypes 'Diyar 95', FLIP06-39C and FLIP03-112C displayed the lowest values for these indices and were noted as the most susceptible genotypes under both conditions. Farshadfar and Sutka (2002) and Gholiouri et al. (2009) considered it the best possible selection criteria where a genotype should be distinguished from the other genotypes.

The indices SSI, SDI, TOL, ATI and SSPI were highly correlated with yield under non-stressed condition. Thus, these indices can be used to identify cultivars in the tolerant group for non-stressed conditions. Therefore, the genotypes FLIP09-51C and FLIP97-503C for TOL, ATI and SSPI, and FLIP97-503C for SSI and SDI were found as the most drought tolerant genotypes under non-stressed condition when genotype was based on the ranking method. The genotypes FLIP06-93C and FLIP03-131C displayed the lower amount of SSI, SDI, TOL, ATI and SSPI and were as the most susceptible genotypes under non-stressed condition. The index SSI has been widely used by researchers to identify sensitive and resistant genotypes (Golabadi et al., 2006; Sio-Se Mardeh et al., 2006; Shirani Rad and Abbasian, 2011). The greater value of SSI indicated the larger drought tolerance under stress and the cultivars with greater SSI were higher drought sensitivity. Yp showed positive correlation with SSI, MP, TOL, STI, GMP, HM, PI and K1STI, while the Ys indicated positive correlation with the HM, YI, YSI, RR and K2STI indices (Sabaghnia et al., 2014).

The indices YI, DI, GM, SNPI, RDI and DTE showed significant and positive correlation with grain yield (Ys) under stress conditions. Based on these indices and ranking method, the genotypes FLIP03-131C, FLIP09-51C, FLIP06-97C and 'Aksu' for YI and DI, FLIP03-131C for GM, FLIP03-131C and FLIP06-97C for SNPI, RDI and DTE were as the most drought tolerant genotypes. The yields of these genotypes under stress conditions have also been high (Table 3). Shiranirad and Abbasian (2011) reported that STI, GMP and YI were able to identify rapeseed cultivars producing high yield under both stress and non-stressed conditions.

In the present study, the GM, RDI, DI and DTE showed significant and positive correlation with yield under stress when stress is too severe (Table 4). FLIP03-131C genotype with high yield under stress produced a lower yield under stressless condition and showed the highest RDI, DI and DTE (Table 3). Positive correlations among the MP, GMP and Yp indices (Toorchi et al., 2012) and positive correlations among the GMP, MP and STI indices (Dehghani et al., 2009) were reported in canola.

\section{Correlation analysis}

A correlation analysis between grain yield and drought tolerance indices is a good criterion for screening the best genotypes. An appropriate index should have a significant correlation with grain yield under both conditions (Mitra, 2001). Correlation coefficients between Yp, Ys, and other quantitative indices of drought tolerance, were calculated to identify the most desirable drought tolerant criteria (Table 4). The results indicated that there were positive and significant correlations among Yp and Ys with MP, MRP, GMP, REI, STI, MSTIk1, MSTIk2 and HM under stressed and non-stressed conditions. However, the indices Pi and RDY showed negative and significant correlation with both Yp and Ys. Therefore, these indices can be used to select genotypes that are better adapted to both conditions.

The results concerning MRP, REI, GMP and STI are in agreement with Bennani et al. (2017). Naghavi et al. (2013) reported that yield in stress and non-stress conditions were significantly and positively correlated with STI, GMP, MP, MSTIk1 and MSTIk2 in corn cultivars. Toorchi et al. (2012) showed that correlation between MP, GMP, Ys and Yp was positive in spring canola. Moreover, significant repeatable correlations were found between yield (Ys) under stress conditions and the drought indices (YI, RDI, DI, GM, DTE, SSI, TOL, SDI, ATI and SSPI). Yield in stress condition (Ys) indicated significantly and positive correlation with the YI, RDI, DI, GM and DTE, while showed significantly and negative correlation with the indices SSI, TOL, SDI, ATI and SSPI.

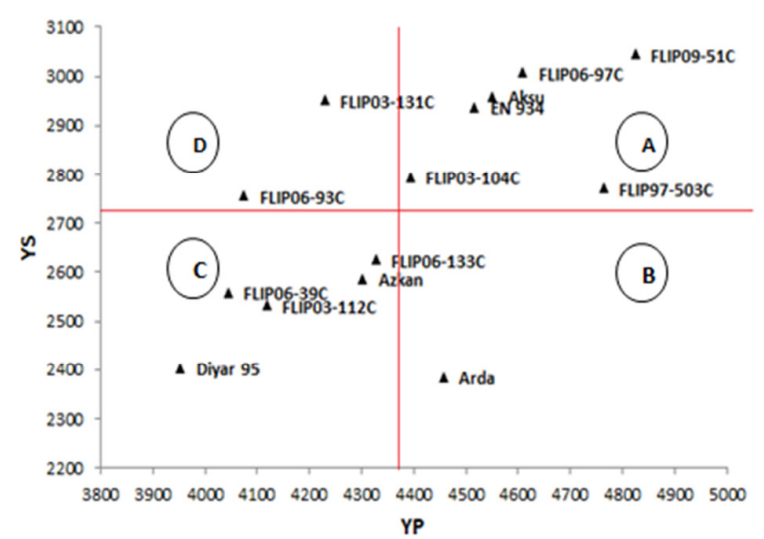

Fig. 1. The relationship between seed yield produced under nostress and drought stress environments 
443

The yield (Yp) under non-stress condition had strong positive correlation with SSI, TOL, SDI, ATI and SSPI, where as it had significant and negative correlation with YI, RDI,DI, GM and DTE. These relationships were affected by the drought density and pointed that genotypes chosen based on these indices are characterized by drought tolerance criteria and will enhance yield for stress conditions. Significant and positive relationships were found between Ys and widely used drought indices MP, GMP, STI, SSI,TOL in many studies (Golabadi et al., 2006; Mohammadi et al., 2010; Farshadfar et al., 2012a; Rahmani et al., 2013). Also, Jafari et al. (2009) and Farshadfar et al. (2014) reported positive significant correlations between Ys and HM, YI, DI, MSTIk1 and MSTIk2 in their drought studies. Strong repeatable significant correlations were found between MP, MRP, GMP, REI and MSTIk1, and these indices have had greater corollation coefficient with grain yield ( $\mathrm{Yp}$ and $\mathrm{Ys}$ ) under both conditions. Similar findings were reported Golabadi et al. (2006), Mevlut and Sait (2011), Drikvand et al. (2012), Moradi et al. (2012), Rahmani et al. (2013), Naghavi et al. (2013) and Farshadfar et al. (2014).

Given these results, the results of the hereby study showed that the indices MP, MRP, GMP, REI and MSTIk1 could be used as suitable indicators for screening drought tolerant chickpea genotypes. Farshadfar et al. (2001) stated that the most suitable indices for selection of drought-tolerant varieties are indicators showing a relatively high correlation with grain yield under both stressful and stress free environments.

Table 3. Mean comparison for yield performances of chickpea genotypes in non-stressed and stressed conditions and twenty-three drought resistance indices

\begin{tabular}{|c|c|c|c|c|c|c|c|c|c|c|c|c|}
\hline Genotype & Yp & $\mathbf{R}$ & Ys & $\mathbf{R}$ & MP & $\mathbf{R}$ & MRP & $\mathbf{R}$ & SSI & $\mathbf{R}$ & TOL & $\mathbf{R}$ \\
\hline EN 934 & 4517.4 & 5 & 2937.6 & 5 & 3727.5 & 5 & 2.11 & 4 & 0.95 & 10 & 1579.8 & 10 \\
\hline FLIP03-112C & 4119.6 & 11 & 2531.9 & 12 & 3325.8 & 12 & 1.86 & 12 & 0.98 & 6 & 1587.7 & 9 \\
\hline FLIP03-131C & 4231.9 & 10 & 2950.9 & 4 & 3591.4 & 7 & 2.05 & 6 & 0.80 & 14 & 1281.0 & 14 \\
\hline FLIP03-104C & 4395.5 & 7 & 2793.6 & 6 & 3594.5 & 6 & 2.02 & 7 & 0.93 & 12 & 1601.9 & 7 \\
\hline FLIP09-51C & 4825.0 & 1 & 3044.6 & 1 & 3934.8 & 1 & 2.22 & 1 & 1.00 & 5 & 1780.4 & 3 \\
\hline FLIP06-133C & 4330.1 & 8 & 2624.6 & 9 & 3477.3 & 8 & 1.95 & 8 & 1.05 & 4 & 1705.5 & 5 \\
\hline FLIP06-97C & 4609.8 & 3 & 3007.2 & 2 & 3808.5 & 2 & 2.16 & 2 & 0.95 & 9 & 1602.6 & 6 \\
\hline FLIP06-93C & 4075.6 & 12 & 2755.8 & 8 & 3415.7 & 11 & 1.94 & 9 & 0.88 & 13 & 1319.8 & 13 \\
\hline FLIP06-39C & 4045.1 & 13 & 2558.8 & 11 & 3302.0 & 13 & 1.86 & 13 & 0.94 & 11 & 1486.2 & 12 \\
\hline FLIP97-503C & 4765.3 & 2 & 2771.2 & 7 & 3768.2 & 3 & 2.09 & 5 & 1.06 & 2 & 1994.1 & 2 \\
\hline 'Arda' & 4457.4 & 6 & 2384.4 & 14 & 3420.9 & 10 & 1.89 & 11 & 1.26 & 1 & 2072.9 & 1 \\
\hline 'Diyar-95' & 3954.4 & 14 & 2402.8 & 13 & 3178.6 & 14 & 1.79 & 14 & 0.96 & 8 & 1551.6 & 11 \\
\hline 'Azkan' & 4303.0 & 9 & 2586.4 & 10 & 3444.7 & 9 & 1.93 & 10 & 1.05 & 3 & 1716.6 & 4 \\
\hline 'Aksu' & 4551.1 & 4 & 2958.3 & 3 & 3754.7 & 4 & 2.13 & 3 & 0.97 & 7 & 1592.8 & 8 \\
\hline Genotype & GMP & $\mathbf{R}$ & REI & $\mathbf{R}$ & STI & $\mathbf{R}$ & MSTIk1 & $\mathbf{R}$ & MSTIk2 & $\mathbf{R}$ & HM & $\mathbf{R}$ \\
\hline EN 934 & 3635.6 & 4 & 1.11 & 4 & 0.70 & 4 & 0.77 & 5 & 0.83 & 4 & 3546.6 & 4 \\
\hline FLIP03-112C & 3204.7 & 12 & 0.87 & 12 & 0.55 & 12 & 0.50 & 12 & 0.49 & 11 & 3091.7 & 12 \\
\hline FLIP03-131C & 3529.1 & 6 & 1.05 & 6 & 0.65 & 6 & 0.61 & 8 & 0.77 & 5 & 3468.2 & 5 \\
\hline FLIP03-104C & 3488.2 & 7 & 1.02 & 7 & 0.64 & 7 & 0.65 & 6 & 0.68 & 7 & 3386.7 & 7 \\
\hline FLIP09-51C & 3826.7 & 1 & 1.23 & 1 & 0.78 & 1 & 0.99 & 1 & 0.98 & 1 & 3722.1 & 1 \\
\hline FLIP06-133C & 3352.9 & 8 & 0.95 & 8 & 0.60 & 8 & 0.59 & 9 & 0.58 & 9 & 3235.2 & 9 \\
\hline FLIP06-97C & 3719.5 & 2 & 1.16 & 2 & 0.73 & 2 & 0.81 & 2 & 0.89 & 2 & 3633.0 & 2 \\
\hline FLIP06-93C & 3345.5 & 9 & 0.94 & 9 & 0.59 & 9 & 0.52 & 11 & 0.62 & 8 & 3277.2 & 8 \\
\hline FLIP06-39C & 3199.5 & 13 & 0.86 & 13 & 0.55 & 13 & 0.47 & 13 & 0.49 & 12 & 3101.9 & 11 \\
\hline FLIP97-503C & 3603.7 & 5 & 1.09 & 5 & 0.69 & 5 & 0.81 & 3 & 0.73 & 6 & 3450.8 & 6 \\
\hline 'Arda' & 3247.5 & 11 & 0.89 & 11 & 0.57 & 11 & 0.61 & 7 & 0.46 & 13 & 3085.3 & 13 \\
\hline 'Diyar-95' & 3049.9 & 14 & 0.79 & 14 & 0.49 & 14 & 0.41 & 14 & 0.41 & 14 & 2928.7 & 14 \\
\hline 'Azkan' & 3324.6 & 10 & 0.93 & 10 & 0.59 & 10 & 0.57 & 10 & 0.53 & 10 & 3210.3 & 10 \\
\hline 'Aksu' & 3666.2 & 3 & 1.13 & 3 & 0.71 & 3 & 0.80 & 4 & 0.84 & 3 & 3580.0 & 3 \\
\hline Genotype & YI & $\mathbf{R}$ & PI & $\mathbf{R}$ & SDI & $\mathbf{R}$ & RDI & $\mathbf{R}$ & DI & $\mathbf{R}$ & GM & $\mathbf{R}$ \\
\hline EN 934 & 1.07 & 5 & 98431.8 & 10 & 0.35 & 11 & 1.04 & 5 & 0.70 & 5 & 5.06 & 6 \\
\hline FLIP03-112C & 0.92 & 12 & 343672.3 & 3 & 0.37 & 5 & 0.98 & 10 & 0.59 & 11 & 5.46 & 4 \\
\hline FLIP03-131C & 1.08 & 4 & 173264.0 & 8 & 0.30 & 14 & 1.12 & 1 & 0.76 & 1 & 6.19 & 1 \\
\hline FLIP03-104C & 1.02 & 6 & 154448.7 & 9 & 0.35 & 9 & 1.02 & 7 & 0.66 & 7 & 5.42 & 5 \\
\hline FLIP09-51C & 1.11 & 1 & 50483.0 & 14 & 0.37 & 6 & 1.01 & 8 & 0.71 & 4 & 4.74 & 10 \\
\hline FLIP06-133C & 0.96 & 9 & 228527.9 & 7 & 0.39 & 4 & 0.97 & 11 & 0.60 & 10 & 4.82 & 9 \\
\hline FLIP06-97C & 1.10 & 2 & 57402.0 & 13 & 0.35 & 12 & 1.05 & 3 & 0.72 & 2 & 4.95 & 7 \\
\hline FLIP06-93C & 1.01 & 7 & 295910.9 & 4 & 0.32 & 13 & 1.09 & 2 & 0.69 & 6 & 5.71 & 2 \\
\hline FLIP06-39C & 0.93 & 11 & 343984.9 & 2 & 0.36 & 7 & 1.01 & 9 & 0.61 & 9 & 5.67 & 3 \\
\hline FLIP97-503C & 1.01 & 8 & 88289.6 & 12 & 0.40 & 2 & 0.93 & 13 & 0.61 & 8 & 4.74 & 11 \\
\hline 'Arda' & 0.87 & 14 & 272602.1 & 5 & 0.46 & 1 & 0.85 & 14 & 0.48 & 14 & 3.56 & 13 \\
\hline 'Diyar-95' & 0.89 & 13 & 548729.9 & 1 & 0.35 & 8 & 1.02 & 6 & 0.59 & 12 & 2.09 & 14 \\
\hline 'Azkan' & 0.95 & 10 & 230253.5 & 6 & 0.39 & 3 & 0.96 & 12 & 0.58 & 13 & 4.45 & 12 \\
\hline 'Aksu' & 1.08 & 3 & 92168.3 & 11 & 0.35 & 10 & 1.04 & 4 & 0.71 & 3 & 4.89 & 8 \\
\hline Genotype & ATI & $\mathbf{R}$ & SSPI & $\mathbf{R}$ & SNPI & $\mathbf{R}$ & RDY & & $\mathbf{R}$ & & DTE & $\mathbf{R}$ \\
\hline EN 934 & 3513636.9 & 6 & 18.0 & 9 & 25.6 & 4 & -132577.3 & & 11 & & 65.1 & 4 \\
\hline
\end{tabular}


444

\begin{tabular}{|cccccccccccc}
444 & & & & & & 62.6 & 10 \\
\hline FLIP03-112C & 3019900.2 & 10 & 17.9 & 10 & 24.6 & 9 & -103362.2 & 3 & 70.3 & 1 \\
\hline FLIP03-131C & 2759397.9 & 13 & 14.5 & 14 & 27.1 & 1 & -124537.2 & 9 & 6 \\
\hline FLIP03-104C & 3343104.8 & 9 & 18.0 & 8 & 25.5 & 5 & -121900.3 & 8 & 64.5 \\
FLIP09-51C & 4227996.7 & 2 & 20.3 & 3 & 25.4 & 7 & -146916.8 & 14 & 63.3 & 9 \\
\hline FLIP06-133C & 3445068.5 & 8 & 19.4 & 5 & 24.2 & 11 & -112813.8 & 7 & 61.2 & 11 \\
\hline FLIP06-97C & 3680962.9 & 4 & 18.3 & 6 & 25.7 & 3 & -138282.6 & 13 & 65.5 & 3 \\
\hline FLIP06-93C & 2719917.9 & 14 & 15.0 & 13 & 25.9 & 2 & -112231.2 & 6 & 68.0 & 2 \\
\hline FLIP06-39C & 2819012.8 & 12 & 16.7 & 12 & 24.9 & 8 & -102629.2 & 2 & 64.1 & 8 \\
\hline FLIP97-503C & 4231237.5 & 1 & 22.4 & 2 & 24.5 & 10 & -130037.3 & 10 & 59.5 & 13 \\
\hline 'Arda' & 4154098.1 & 3 & 23.6 & 1 & 21.6 & 13 & -106410.4 & 4 & 53.8 & 14 \\
\hline 'Diyar-95' & 2935822.9 & 11 & 17.6 & 11 & 15.4 & 14 & -93877.3 & 1 & 64.5 & 7 \\
\hline 'Azkan' & 3490273.4 & 7 & 19.5 & 4 & 23.6 & 12 & -110746.4 & 5 & 60.8 & 12 \\
\hline 'Aksu' & 3653654.4 & 5 & 18.2 & 7 & 25.5 & 6 & -134590.2 & 12 & 65.1 & 5 \\
\hline
\end{tabular}

Yp: Potential Yield, Ys: Stress Yield, MP: Mean Productivity, MRP: Mean relative performance, SSI: Stress Susceptibility Index, TOL: Tolerance, GMP: Geometric Mean Productivity RI: Relative efficiency index STI: Stress Tolerance Index, MSTIk1: Modified stress tolerance index 1, MISTIk2: Modified stress tolerance index 2 HM: Harmonic mean of yield, YI: Yield Index, PI: Superiority Index, SDI: Sensitivity drought index, RDI: Relative Drought Index, DI: Drought Resistance Index, GM: Golden mean, ATI: Abiotic Tolerance Index, SSPI: Stress Susceptibility Percentage Index, SNPI: Stress/non-stress production index, RDY: Relative decrease in yield, DTE: Drought tolerance efficiency, R: Ranks.

Table 4. Simple correlation coefficients of stress indices with seed yield of 14 chickpea genotypes

\begin{tabular}{|c|c|c|c|c|c|c|c|c|}
\hline & $\mathrm{YP}$ & YS & MP & MRP & SSI & TOL & GMP & REI \\
\hline YS & -0.072 & & & & & & & \\
\hline MP & 0.717 & 0.644 & & & & & & \\
\hline MRP & $0.611^{*}$ & $0.730^{\prime \prime}$ & 0.979 & & & & & \\
\hline SSI & $0.530^{*}$ & -0.530 & 0.036 & -0.129 & & & & \\
\hline TOL & $0.760^{\prime \prime}$ & $-0.702^{\prime \prime}$ & 0.092 & -0.039 & 0.724 & & & \\
\hline GMP & 0.523 & $0.810^{*}$ & 0.967 & $0.982^{\circ}$ & -0.126 & -0.154 & & \\
\hline REI & $0.607^{*}$ & $0.734^{*}$ & $0.979^{*}$ & $0.999^{\prime \prime}$ & -0.127 & -0.044 & $0.983^{\prime \prime}$ & \\
\hline STI & $0.272^{*}$ & 0.877 & $0.822^{*}$ & $0.815^{*}$ & -0.099 & -0.377 & 0.906 & $0.823^{*}$ \\
\hline MSTIk1 & $0.577^{*}$ & $0.635^{\circ}$ & 0.886 & $0.819^{*}$ & 0.182 & -0.001 & $0.873^{\prime \prime}$ & 0.830 \\
\hline MSTIk2 & $0.264^{*}$ & 0.923 & $0.848^{*}$ & $0.903^{*}$ & -0.346 & -0.412 & 0.938 & $0.910^{*}$ \\
\hline $\mathrm{HM}$ & $0.350^{*}$ & $0.903^{*}$ & $0.900^{*}$ & $0.940^{*}$ & $-0.244^{*}$ & -0.338 & $0.981^{" \prime}$ & $0.943^{*}$ \\
\hline YI & 0.168 & $0.853^{\circ}$ & $0.725^{*}$ & $0.847^{*}$ & $-0.593^{*}$ & -0.436 & $0.830^{*}$ & $0.844^{*}$ \\
\hline $\mathrm{Pi}$ & -0.744 & $-0.432^{\prime \prime}$ & -0.873 & $-0.831^{\prime \prime}$ & $-0.263^{*}$ & $-0.250^{\prime \prime}$ & -0.823 & $-0.825^{\prime \prime}$ \\
\hline SDI & $0.661^{*}$ & -0.768 & -0.030 & -0.157 & $0.793^{*}$ & 0.972 & -0.259 & -0.160 \\
\hline RDI & -0.486 & $0.609^{*}$ & 0.054 & $0.242^{\circ}$ & $-.0954^{*}$ & $-0.743^{\circ}$ & $0.232^{\circ}$ & $0.237^{\circ}$ \\
\hline DI & -0.394 & $0.905^{\circ}$ & $0.331^{*}$ & $0.471^{*}$ & $-0.811^{*}$ & -0.870 & $0.533^{\circ}$ & $0.471^{*}$ \\
\hline GM & -0.225 & $0.579^{\prime \prime}$ & $0.233^{\circ}$ & $0.281^{"}$ & -0.165 & -0.538 & $0.377^{"}$ & $0.277^{\prime \prime}$ \\
\hline ATI & $0.899^{*}$ & -0.370 & $0.431^{*}$ & $0.277^{*}$ & $0.792^{\circ}$ & $0.883^{*}$ & $0.212^{\circ}$ & $0.277^{*}$ \\
\hline SSPI & $0.770^{*}$ & -0.684 & 0.112 & -0.031 & $0.784^{*}$ & $0.995^{\circ}$ & -0.133 & $0-.035$ \\
\hline SNPI & 0.103 & $0.494^{\circ}$ & $0.424^{*}$ & $0.438^{*}$ & 0.116 & $-0.248^{*}$ & $0.508^{*}$ & 0.436 \\
\hline RDY & -0.523 & $-0.810^{*}$ & -0.967 & $-0.979 "$ & 0.123 & 0.154 & -0.998 & -0.983 \\
\hline \multirow[t]{2}{*}{ DTE } & $-0.661^{*}$ & $0.768^{*}$ & 0.030 & 0.157 & -0.793 & -.972 & $.259^{\circ}$ & .160 \\
\hline & STI & MSTIk1 & MSTIk2 & HM & YI & $\mathrm{Pi}$ & & SDI \\
\hline MSTIk1 & 0.912 & & & & & & & \\
\hline MSTIk2 & $0.910^{*}$ & $0.787^{\prime \prime}$ & & & & & & \\
\hline $\mathrm{HM}$ & $0.932^{*}$ & $0.825^{\prime \prime}$ & 0.967 & & & & & \\
\hline YI & $0.670^{*}$ & 0.496 & $0.889^{*}$ & $0.873^{\prime \prime}$ & & & & \\
\hline $\mathrm{Pi}$ & -0.645 & -0.699 & -0.617 & $-0.747^{*}$ & -0.538 & & & \\
\hline SDI & $-0.453^{*}$ & -0.110 & -0.501 & -0.424 & $-0.527^{\prime \prime}$ & $-0.208^{\circ}$ & & \\
\hline RDI & 0.171 & -0.124 & $0.445^{*}$ & $0.357^{*}$ & $0.710^{*}$ & 0.168 & & $-0.793^{*}$ \\
\hline DI & $0.607^{\prime \prime}$ & $0.291^{*}$ & $0.745^{*}$ & $0.665^{\circ}$ & $0.795^{\prime \prime}$ & -0.070 & & $-0.929^{*}$ \\
\hline GM & 0.490 & $0.215^{\circ}$ & $0.469^{*}$ & $0.473^{*}$ & 0.389 & -0.332 & & $-0.442^{\circ}$ \\
\hline ATI & 0.061 & $0.436^{\prime \prime}$ & $0-.074$ & 0.034 & $-0.235^{\circ}$ & -0.507 & & $0.818^{*}$ \\
\hline SSPI & -0.325 & 0.056 & -0.396 & $-0.315^{\circ}$ & -0.460 & -0.269 & & $0.970^{*}$ \\
\hline SNPI & $0.534^{*}$ & $0.361^{" \prime}$ & $0.497^{\circ}$ & $0.552^{\circ}$ & $0.391^{*}$ & -0.606 & & -0.146 \\
\hline RDY & -0.914 & -0.890 & -0.946 & $-0.977^{*}$ & $-0.821^{*}$ & $0.799^{\circ}$ & & $0.262^{*}$ \\
\hline \multirow[t]{2}{*}{ DTE } & $.453^{*}$ & .110 & $.501^{\prime \prime}$ & .424 & $.527^{*}$ & $.208^{\circ}$ & & -1.000 \\
\hline & RDI & DI & GM & ATI & SSPI & SNPI & & RDY \\
\hline DI & $0.858^{* *}$ & & & & & & & \\
\hline GM & $0.230^{*}$ & $0.491^{* *}$ & & & & & & \\
\hline ATI & $-0.768^{* *}$ & $-0.684^{* *}$ & $-0.405^{* *}$ & & & & & \\
\hline SSPI & $-0.797^{* *}$ & $-0.879^{* *}$ & $-0.516^{* *}$ & $0.914^{* *}$ & & & & \\
\hline SNPI & 0.001 & $0.275^{* *}$ & $0.917^{* *}$ & -0.076 & $-0.218^{*}$ & & & \\
\hline RDY & $-.0225^{*}$ & $-0.534^{* *}$ & $-0.357^{* *}$ & $-0.218^{*}$ & 0.131 & $-0.485^{* *}$ & & \\
\hline DTE & $.793^{* *}$ & $.929^{* *}$ & $.442^{* *}$ & $-.818^{* *}$ & $-.970^{* *}$ & .146 & & $-.262^{* *}$ \\
\hline
\end{tabular}




\section{Conclusions}

The variance and correlation analysis results used in the research showed that there are statistical differences between genotypes for MP, MRP, GMP, REI, STI, MSTIK1, MSTIK2 and HM indices and these indices showed strong correlations with yields of both environments. The results of the study especially indicated that indices MP, MRP, GMP, REI and MSTIK1 can be used as the most suitable indicators for selecting drought tolerant chickpea genotypes under both stressed and nonstressed environments. The indices PI and RDY showed negative and significant correlation with yields under both conditions. However, GM, RDI, DI and DTE indices show significant and positive correlation with yield under stress only when stress is too severe. These indices can also be considered as suitable criteria for selecting drought-tolerant and highly efficient genotypes in environments where drought is predominant. In consideration to all indices, FLIP09-51C, FLIP06-97C and 'Aksu' cultivar exhibited the best rank, and hence they were defined as the most tolerant genotypes, while 'Diyar 95', FLIP06-39C and FLIP03-112C genotypes were the most sensitive for drought.

\section{References}

Bennani S, Nsarellah N, Jlibene M, Tadesse W, Birouk A, Ouabbou H (2017). Efficiency of drought tolerance indices under different stress severities for bread wheat selection. Australian Journal of Crops Science $\operatorname{AJCS} 11(04): 395-405$.

Blum A (1996). Crop responses to drought and the interpretation of adaptation. Plant Growth Regulators 20:135-148.

Bouslama M, Schapaugh WT (1984). Stress tolerance in soybean. Part 1: Evaluation of three screening techniques for heat and drought tolerance. CropScience 24:933-937.

Dadbakhsh A, Yazdansepas A, Ahmadizadeh M (2011). Study drought stress on yield of wheat (Triticum aestivum L.) genotypes by drought tolerance indices. Advances in Environmental Biology 5(7):18041810.

Drikvand R, Doosty B, Hosseinpour T (2012). Response of rainfed wheat genotypes to drought stress using drought tolerance indices. Journal of Agricultural Science 4(7):126.

FAO (2017). The Food and Agriculture Organization of the United Nations. Retrieved at 05 Dec 2017 from http://www.fao.org/faostat/en/\#data/QC/visualize.

Farshadfar E, Ghanadha M, Zahravi M, Sutka J (2001). Generation mean analysis of drought tolerance in wheat. Acta Agronomica Hungarica 49(1):59-66.

Farshadfar E, Sutka J (2002). Multivariate analysis of drought tolerance in wheat substitution lines. Cereal Research Communications 31:33-39.

Farshadfar E, Javadinia J (2011). Evaluation of chickpea (Cicer arietinum L.) genotypes for drought tolerance. Seed and Plant Improvement Journal 27(4):517-537.

Farshadfar E, Elyasi P (2012). Screening quantitative indicators of drought tolerance in bread wheat ( $T$. aestivum) landraces. Pelagia Research Library. European Journal of Experimental Biology 2(3):577-584.

Farshadfar E, Farshadfar M, Dabiri S (2012a). Comparison between effective selection criteria of drought tolerance in bread wheat landraces of Iran. Annual Biological Research 3(7):3381-3389.

Farshadfar E, Sheibanirad A, Soltanian M (2014). Screening landraces of bread wheat genotypes for drought tolerance in the field and laboratory. International Journal of Farming and Allied Sciences 3(3):304311.

Fernandez GCJ (1992). Effective selection criteria for assessing plant stress tolerance. In: Kuo CG (Ed). Adaptation of Food Crops to Temperature and Water Stress. Shanhua: Asian Vegetable Research and Development Center. Taiwan Publication 93(410):257-270.

Fischer RA, Wood JT (1979). Drought resistance in spring wheat cultivars III. Yield association with morphological traits. Australian Journal of Agricultural Research 30: 1001-1020.

Fischer RA, Maurer R (1978). Drought resistance in spring wheat cultivars. Australian Journal of Agricultural Research 29:897-912.

Gavuzzi P, Rizza F, Palumbo M, Campaline RG, Ricciardi GL, Borghi B (1997). Evaluation of field and laboratory predictors of drought and heat tolerance in winter cereals. Canadian Journal of Plant Science 77:523531.

Gholipouri A, Sedghi M, Sharifi R S, Nazari NM (2009). Evaluation of drought tolerance indices and their relationship with grain yield in wheat cultivars. Recent Research in Science and Technology 1(4):195-198.

Golabadi M, Arzani A, Maibody SAM (2006). Assessment of drought tolerance in segregating populations in durum wheat. African Journal of Agricultural Research 5:162-171.

Hossain ABS, Sears AG, Cox TS, Paulsen GM (1999). Desiccation tolerance and its relationship to assimilate partitioning in winter wheat. CropScience 30:622-627.

Jafari A, Paknejad F, Jami Al-Ahmadi M (2009). Evaluation of selection indices for drought tolerance of corn (Zea mays L.) hybrids. International Journal of Plant Production 3(4):33-38.

Lan J (1998). Comparison of evaluating methods for agronomic drought resistance in crops. Acta Agriculturae Boreali-occidentalis Sinica 7:85-87.

Lin CS, Binns MR, Lefkovitch LP (1986). Stability analysis: where do we stand? CropScience 26:894900.

Mevlüt A, Sait Ç (2011). Evaluation of drought tolerance indices for selection of Turkish oat (Avena sativa L.) landraces under various environmental conditions. Zemdirbyste Agriculture 98(2):157-166.

Mitra J (2001). Genetics and genetic improvement of drought resistance in crop plants. Current Science India 80:758-763.

Mohammadi R, Armion M, Kahrizi D, Amri A (2010). Efficiency of screening techniques for evaluating durum wheat genotypes under mild drought condition. International Journal of Plant Production 4(1):1124.

Mollasadeghi V, Valizadeh M, Shahryariand RA, Imani A (2011). Evaluation of end drought tolerance of 12 wheat genotypes by stress in dices.MEJSR 7(2):241-247.

Moosavi SS, Samadi YB, Naghavi MR, Zali AA, Dashti H, Pourshahbazi A (2008). Introduction of new indices to identify relative drought tolerance and resistance in wheat genotypes. Desert 12:165-178.

Moradi H, Akbari GA, Khorasani SK, Ramshini HA (2012). Evaluation of drought tolerance in corn (Zea mays L.) new hybrids with using stress tolerance indices. European Journal of Sustainable Develpment $1(3): 543-560$. 
446

Naghavi MR, Pouraboughadareh A, Khalili M (2013). Evaluation of drought tolerance indices for screening some of corn (Zea mays L.) cultivars under environmental conditions. Notulae Scientia Biologicae 5(3):388-393.

Rahmani S, Farshadfar E, Jowhar MM (2013). Locating QTLs controlling yield based indicators of drought tolerance in agropyron using wheat agropyron disomic addition lines. International Journal of Agriculture and CropSciences 5(9):1028-1033.

Rosielle AA, Hamblin J (1981). Theoretical aspects of selection for yield in stress and non-stress environments. CropScience 21:943-946.

Shirani Rad AH, Abbasian A (2011). Evaluation of drought tolerance in winter rapeseed cultivars based on tolerance and sensitivity indices. Žemdirbystè Agriculture 98:41-48.
Sio-Se Mardeh A, Ahmadi A, Poustini K, Mohammadi V (2006). Evaluation of drought resistance indices under various environmental conditions. Field Crops Research 98:222-229.

Toorchi M, Naderi R, Kanbar A Shakiba MR (2012). Response of spring canola cultivars to sodium chloride stress. Annals of Biological Research 2:312-322.

Zdemur S, Karadavut U (2003). Comparison of the performance of autumn and spring sowing of chickpeas in a temperate region. Turkish Journal of Agriculture and Forestry 27:345-352. 